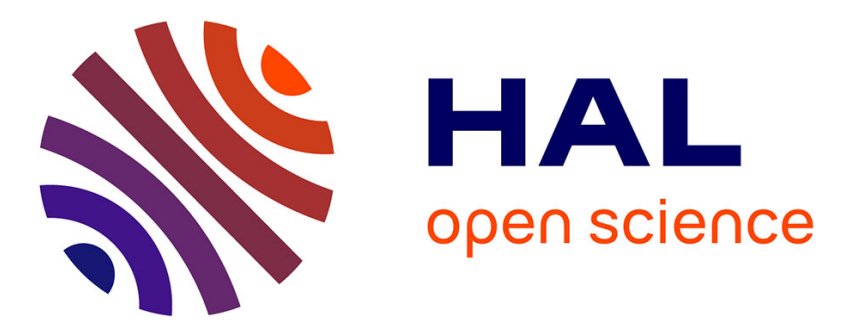

\title{
On the identification of the double donor state of EL2 in p type GaAs
}

\author{
A. Bencherifa, G. Brémond, A. Nouailhat, G. Guillot, A. Guivarc'H, A. \\ Regreny
}

\section{- To cite this version:}

A. Bencherifa, G. Brémond, A. Nouailhat, G. Guillot, A. Guivarc'H, et al.. On the identification of the double donor state of EL2 in p type GaAs. Revue de Physique Appliquée, 1987, 22 (8), pp.891-895. 10.1051/rphysap:01987002208089100 . jpa-00245629

\section{HAL Id: jpa-00245629 https://hal.science/jpa-00245629}

Submitted on 1 Jan 1987

HAL is a multi-disciplinary open access archive for the deposit and dissemination of scientific research documents, whether they are published or not. The documents may come from teaching and research institutions in France or abroad, or from public or private research centers.
L'archive ouverte pluridisciplinaire HAL, est destinée au dépôt et à la diffusion de documents scientifiques de niveau recherche, publiés ou non, émanant des établissements d'enseignement et de recherche français ou étrangers, des laboratoires publics ou privés. 
Classification

Physics Abstracts

$71.55-72.80 \mathrm{E}-78.20 \mathrm{~J}$

\title{
On the identification of the double donor state of EL2 in p type GaAs
}

\author{
A. Bencherifa, G. Brémond, A. Nouailhat, G. Guillot, A. Guivarc'h $\left(^{+}\right)$and A. Regreny $\left(^{+}\right)$
}

INSA de Lyon, Laboratoire de Physique de la Matière, Bât. 502, 20, avenue Albert-Einstein, 69621 Villeurbanne Cedex, France

$\left(^{+}\right)$CNET Lannion B, ICM/MPA, 22301 Lannion, France

(Reçu le 16 janvier 1987, accepté le 23 mars 1987)

\begin{abstract}
Résumé. - En combinant des expériences de DLTS, DLOS, ODLTS et TSCAP sur des matériaux GaAs LEC de type $\mathrm{p}$, nous avons montré que : i) ce matériau contient un défaut natif $\mathrm{HM} 1 \mathrm{à} E_{\mathrm{v}}+0,52 \mathrm{eV}$ qui n'existe pas dans les cristaux élaborés dans des conditions riches en $\mathrm{Ga}$;ii) un piège à porteur minoritaire est détecté à $E_{\mathrm{c}}-0,82 \mathrm{eV}$ avec la même concentration ; nous avons montré que ce défaut est le niveau EL2 ; iii) à partir d'expériences de photocapacité et de TSCAP, nous démontrons que HM1 est l'état double donneur $(++/+)$ de EL2.

Abstract. - Combining deep level transient spectroscopy (DLTS), deep level optical spectroscopy (DLOS), optical DLTS (ODLTS) and thermally stimulated capacitance (TSCAP) on p type LEC GaAs we have shown that : i) this material contains a native hole trap $\mathrm{HM} 1$ at $E_{\mathrm{v}}+0.52 \mathrm{eV}$ which does not exist in crystals grown under Ga-rich conditions ; ii) a minority carrier trap is detected at $E_{\mathrm{c}}-0.82 \mathrm{eV}$ with the same concentration ; this level is shown to be the electron trap EL2; iii) on the basis of photocapacitance and TSCAP measurements it is demonstrated that HM1 is the double donor state $(++/+)$ of EL2.
\end{abstract}

\section{Introduction.}

The semi-insulating properties of melt-grown undoped $\mathrm{GaAs}$ are considered to be due to the presence of the mid-gap level EL2 which compensates shallow acceptors. The formation mechanism of this defect seems mainly determined by melt stœchiometry. Its concentration is enhanced under As-rich conditions [1]. The exact nature of this electron trap has been the subject of many controversial studies [2]. It is now more or less admitted that this defect involve the As-antisite defect $\mathrm{As}_{\mathrm{Ga}}$ in an isolated [3] or a complex form [4]. Moreover, the unusual optical properties of EL2 like the persistent quenching of the photocapacitance [5] or the optical absorption [6] under illumination at $1.18 \mathrm{eV}$ at low temperature indicate a metastable excited state.

The aim of this paper is to report systematic experiments on the deep levels located in the lower half of the energy gap in LEC GaAs and acting as hole traps in $p$ type GaAs. These studies are very important relatively to the identification of the double donor $(++/+)$ state of EL2 which is known as the single donor $(+/ 0)$ state of the isolated or complexed antisite $\mathrm{As}_{\mathrm{Ga}}$.

We have therefore investigated by thermal and optical deep level spectroscopy (DLTS, ODLTS, DLOS and TSCAP) the nature of deep traps in several p-type LEC GaAs. We report the electrical and optical properties of the main hole trap found at $E_{\mathrm{v}}+0.52 \mathrm{eV}$ which we identify as the double donor state of EL2 confirming unambiguously previous results of Weber et al. [7], Wosinski et al. [8] and Lagowski [9] based on photo-EPR and on photocapacitance measurements. Very recently, Osaka et al. [10] also detected this trap in p-type LEC GaAs and identified it as the double donor state of the main electron trap EL2. But, in fact, this identification is only based on the dependence of this trap on the melt composition and impurities.

\section{Experimental procedure.}

2.1 MATERials. - Crystals used in this study are grown by the LEC method under conditions of either melt stœchiometry or Ga-rich melt. $\mathrm{Zn}$ is 
introduced as a dopant to obtain a free hole concentration of about $(5-10) \times 10^{16} \mathrm{~cm}^{-3}$ depending the crystal.

2.2 CAPACitance MEASUREMENTS. - The capicitance measurements are carried out on Schottky diodes made by $\mathrm{Al}$ evaporation on the surface after appropriate degreasing and etching treatments. Ohmic contacts are obtained by allowing small dots of an Ag-Zn-In alloy on the sample sides before making the Schottky barrier. Only Schottky diodes with low leakage current (typically $1 \mu \mathrm{A}$ at $V_{\mathrm{R}}=$ $-2 \mathrm{~V})$ are selected for a capacitance measurements by systematic studies of $I(V)$ characteristics. On the same materials, an epilayer of $\mathrm{n}^{+}$type doped with $\mathrm{Si}$ have been grown by MBE at CNET Lannion. In this case, the ohmic contact on the $p$-side are formed by alloying In (during the MBE growth at $600{ }^{\circ} \mathrm{C}$ the samples are sticked by In) and the ohmic contact on the $\mathrm{n}^{+}$side is formed by evaporating an AuGeNi alloy and heating at $450^{\circ} \mathrm{C}$ during $1 \mathrm{~min}$ in an $\mathrm{H}_{2}$ atmosphere. The $\mathrm{n}^{+}-\mathrm{p}$ junctions are mesa type and defined by standard photolithographic techniques.

The electrical and optical transient capacitance measurements have been performed on two experimental set up which have been already described in previous works $[11,12]$.

\section{Results and discussion.}

3.1 TRANSIENT CAPACITANCE RESUlts. - In stœchiometric crystals, two main hole traps are detected by DLTS which we denote as HM1 and HM2 (Fig. 1). The apparent activation energy $E_{\mathrm{Pa}}$ and capture cross section $\sigma_{\mathrm{p} \infty}$ deduced from the Arrhenius plots are respectively $0.52 \pm 0.02 \mathrm{eV}$ and $3 \times 10^{-15} \mathrm{~cm}^{2}$ for HM1, $0.62 \pm 0.02 \mathrm{eV}$ and $4 \times$

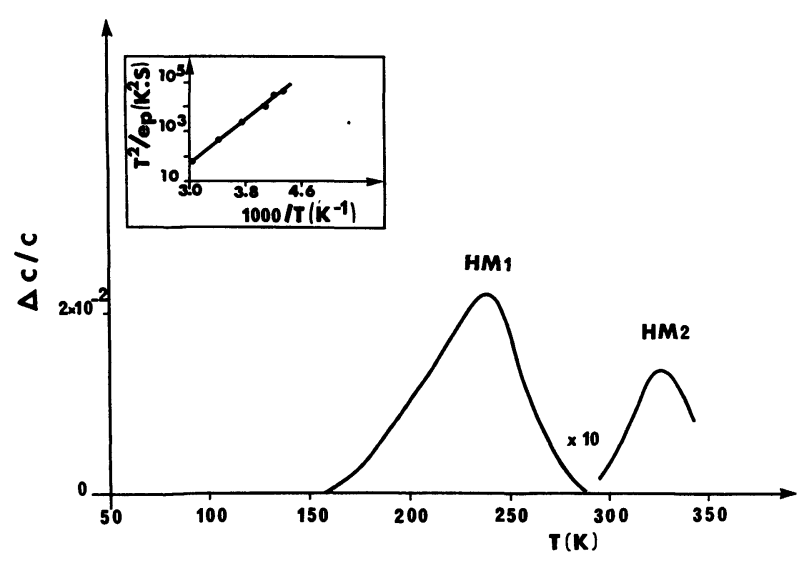

Fig. 1. - DLTS spectrum recorded on a $n^{+}-p$ junction made by MBE on $p$ type LEC GaAs (Experimental conditions : emission rate $: 0.86 \mathrm{~s}^{-1}$; reverse bias : $-2 \mathrm{~V}$; excitation pulse : $+2 \mathrm{~V}$; with pulse : $0.1 \mathrm{~ms}$ ). Insert : thermal signature $T^{2} /$ ep as a function of $1 / T$ for the HM1 trap.
$10^{-16} \mathrm{~cm}^{2}$ for HM2. The corresponding concentration are $4 \times 10^{16} \mathrm{~cm}^{-3}$ for HM1 and $5 \times 10^{15} \mathrm{~cm}^{-3}$ for HM2 taking into account $\lambda$ correcting factor for a free hole concentration of $1.5 \times 10^{17} \mathrm{~cm}^{-3}$. Special interest has been devoted to the HM1 level taking into account the recent results of Lagowsky et al. [9]. First, we notice that the HM1 activation energy decreases with increasing filling pulse amplitude. This effect can be explained in terms of field assisted thermal emission of trap in the deplection layer [13]. In order to calculate the most accurate values for $E_{\mathrm{A}}$ and $\sigma_{\mathrm{p} \infty}$, we have used the results obtained with the lowest electric field.

Another very important result is that HM1 is not detected in the Ga-rich crystals.

Figure 2 shows the optical photoionization crosssection $\sigma_{\mathrm{p} 1}^{0}(h \nu)$ of HM1 measured by electrical DLOS method in $p$ type GaAs. This curve is obtained by the difference between the DLOS spectrum at $150 \mathrm{~K}$ and the DLOS response of HM2 included in the DLOS spectrum measured at $270 \mathrm{~K}$. The main feature of this experimental curve is the unique threshold at $E_{\mathrm{v}}+(0.54 \pm 0.02) \mathrm{eV}$. The shape of this curve clearly rules out the possibility of the association of HM1 with the $\mathrm{Fe}^{2+}$ acceptor level which has a DLTS signature very close to that of HM1 because the $\sigma_{\mathrm{p}}^{0}(h \nu)$ curve of $\mathrm{Fe}^{2+/ 3+}$ reveals two thresholds at $0.46 \mathrm{eV}$ and $0.85 \mathrm{eV}$ corresponding to the photoionization of holes to the ${ }^{5} \mathrm{E}$ ground state and ${ }^{5} \mathrm{~T}_{2}$ excited state of the $\mathrm{Fe}^{2+}$ acceptor level [14]. So, HM1 is a defect different from the $\mathrm{Fe}^{2+}$ acceptor level.

To detect minority carrier traps, we have used ODLTS in Schottky barriers and DLTS under minority carrier injection in $\mathrm{n}^{+}-\mathrm{p}$ junctions. Both experiments give an electron trap at $E_{\mathrm{c}}-0.82 \mathrm{eV}$

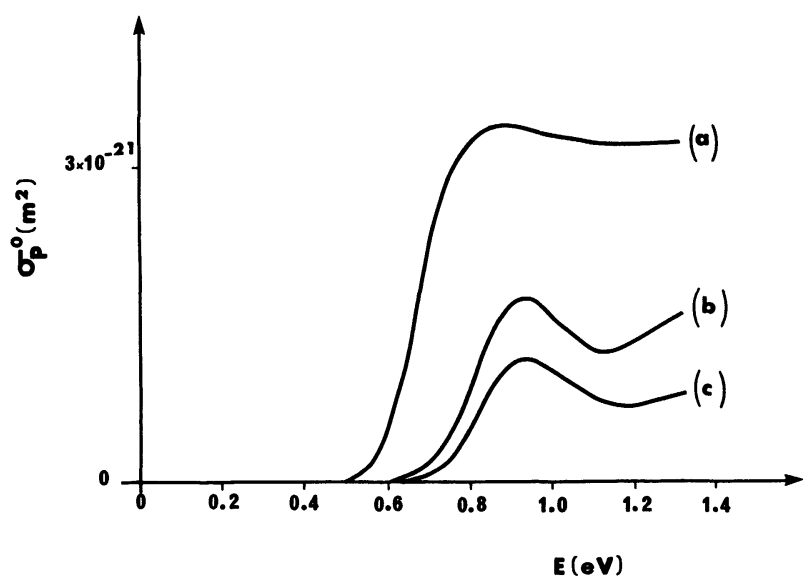

Fig. 2. - Photoionization cross section curves $\sigma_{\mathrm{p}}^{0}(h \nu)$ measured by DLOS : (a) for the hole trap HM1 in p type LEC GaAs at $150 \mathrm{~K}$ (see the next for experimental details) ; (b) for the electron trap EL2 in n type GaAs at $305 \mathrm{~K}$ from [15], (c) for the minority carrier trap detected in $p$ type LEC GaAs at $270 \mathrm{~K}$. 
with a capture cross section $\sigma_{\text {no }}=2 \times 10^{-13} \mathrm{~cm}^{2}$. This signature coincides very well with that of the EL2 [15] (Fig. 3) and we identify this electron trap as the EL2 level. This is confirmed by the fact that the optical cross section $\sigma_{\mathrm{p} 2}^{0}(h \nu)$ of this defect measured at $270^{\circ} \mathrm{K}$ is the same as the one measured for EL2 [16] (Fig. 2). The estimated concentration of this minority carrier trap is identical to that of HM1 suggesting that these two levels could be due to two different charge states of the same defect.

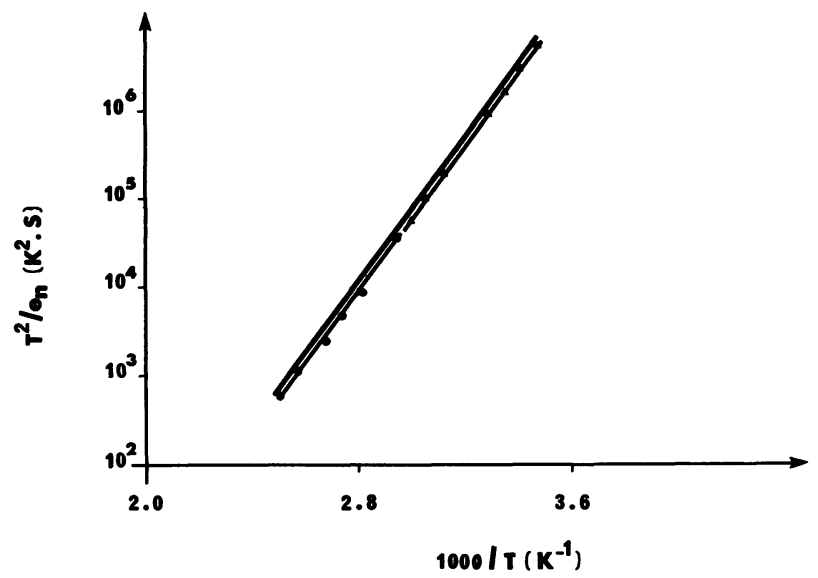

Fig. 3. - Thermal signature for the main minority carrier trap detected in p type LEC GaAs : (A) by ODLTS with $h \nu=0.95 \mathrm{eV} \quad\left(E_{\mathrm{na}}=0.824 \mathrm{eV} ; \sigma_{\mathrm{na}}=2 \times 10^{-13} \mathrm{~cm}^{2}\right)$; $(\bullet)$ by minority carrier injection DLTS $\left(E_{\mathrm{na}}=0.828 \mathrm{eV}\right.$, $\sigma_{\mathrm{na}}=2.5 \times 10^{-13} \mathrm{~cm}^{2}$ ), solid line : thermal signature of the EL2 level after [2] $\left(E_{\mathrm{na}}=0.825 \mathrm{eV} ; \sigma_{\mathrm{na}}=1.7 \times\right.$ $10^{-13} \mathrm{~cm}^{2}$ ).

The behaviour of photocapacitance transients at low temperature confirms the presence of EL2 and the fact that HM1 could be the lower double donor state $(+/++)$ of the $\mathrm{As}_{\mathrm{Ga}}$ defect in isolated or complexed form since the midgap level EL2 has been identified with the single donor state of $\mathrm{As}_{\mathrm{Ga}}(0 /+)[3,4]$. Figure $4 \mathrm{a}$ represents the well known photocapacitance quenching effect of EL2 in $\mathrm{n}$ type GaAs under photoexcitation at $1.17 \mathrm{eV}$ at $77 \mathrm{~K}$ [5]. The initial increase of the capacitance caused by photoionization of EL2 is followed by a slow decrease corresponding to the EL2 transition to the neutral metastable state. In $p$ type GaAs the behaviour is nearly opposite : the HM1 trap is originally positively charged and the transition under $1.18 \mathrm{eV}$ to the metastable state is detected as a slow increase of capacitance [9] (Fig. 4b). As in $n$ type, no quenching effect is visible at $T=150 \mathrm{~K}$. Another kind of experiment, as illustrated in figure $4 \mathrm{c}$, explains the photoquenching effect in p type GaAs. The $0.85 \mathrm{eV}$ illumination induces the transition of the double ionized state $(++)$ to the single state $(+)$ which allows the second photoionization process involving the $(+/ 0)$ state. Subsequently, the $1.18 \mathrm{eV}$

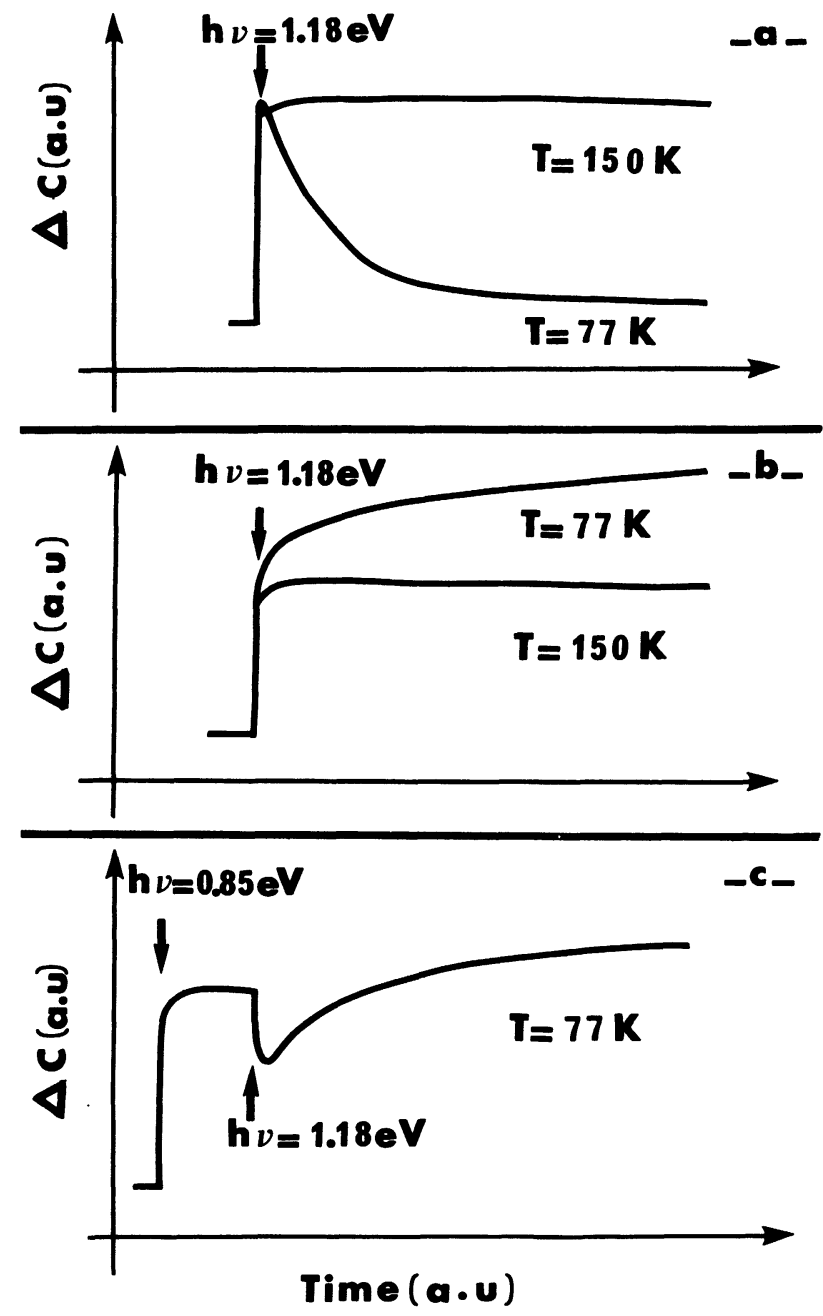

Fig. 4. - Capacitance transient corresponding to deep level photoexcitation to the persistent metastable state for: (a) $n$ type GaAs ; (b) and (c) p type GaAs.

illumination ionizes partially the neutral state leading to a rapid capacitance decrease followed by a slow transfer to the neutral metastable state.

Therefore, we propose that HM1 and EL2 are two levels corresponding to different charge states of the $\mathrm{As}_{\mathrm{Ga}}$ defect in an isolated or complexed form as already suggested but non demonstrated by different authors [7-10].

3.2 TSCAP RESULTS. - Because the fact that $\sigma_{\mathrm{p} 2}^{0}$ of EL2 is lower than $\sigma_{\mathrm{p} 1}^{0}$ of HM1 it is not possible to show directly by DLOS with sufficient accuracy that HM1 and EL2 are two different charge state of the same defect or not : it is very difficult indeed to know if the low temperature DLOS spectrum contains or not $\sigma_{\mathrm{p} 2}^{0}$. Therefore we have used a procedure based on TSCAP measurements. Following the experimental sequences given in figure 5 , it is possible to interpret the results unambiguously on the framework of only one hypothesis (see TSCAP equations in Fig. 5). The main idea is to use the fact that we are able to put all the EL2 


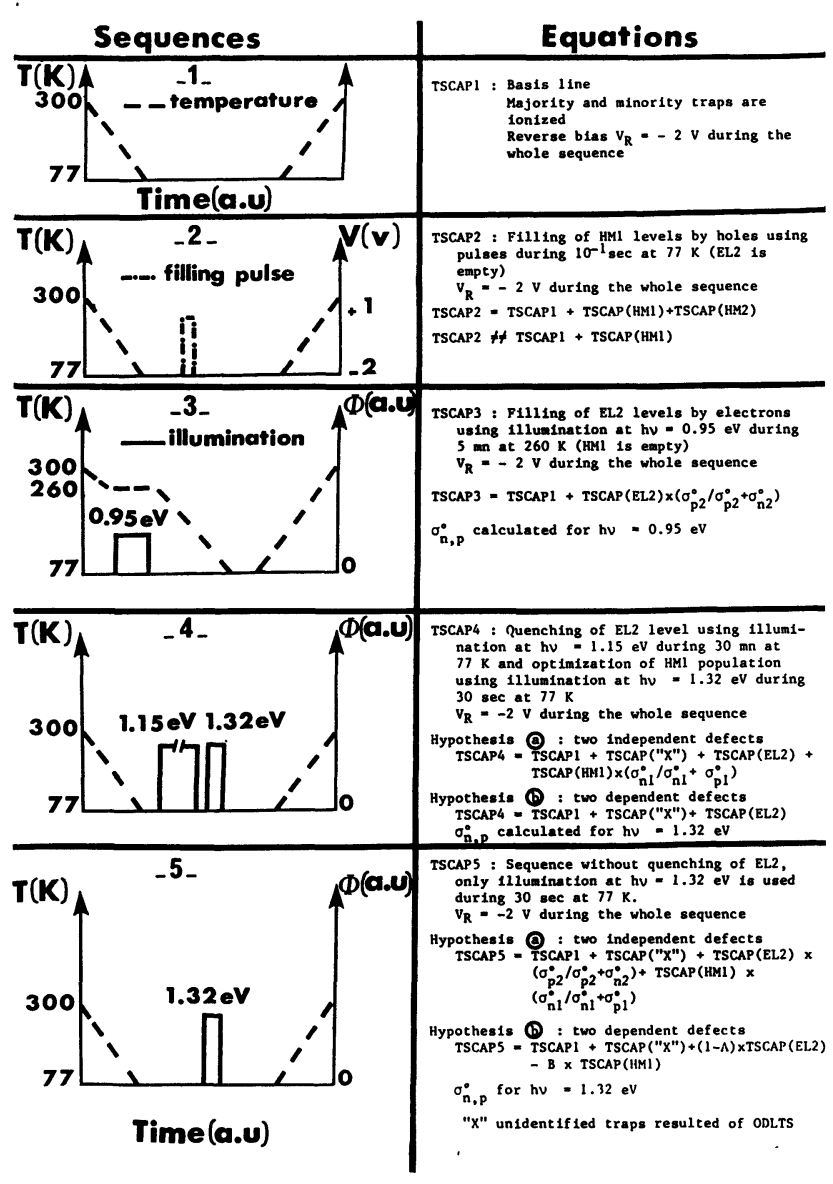

Fig. 5. - Sequences of the various experimental conditions for TSCAP experiments. $\sigma_{\mathrm{n}}^{0}$ and $\sigma_{\mathrm{p}}^{0}$ : optical ionization cross sections corresponding to the transition from the level to the conduction band and from the valence band to the level respectively (the indices 1 and 2 are related to HM1 and EL2 respectively).

centres in the charge state full of electrons at low temperature using the quenching effect [5]. Thus if HM1 is the double donor charge state of EL2, we do not have any TSCAP step due to HM1 centres. The photo-quenching is made by illumination at $1.15 \mathrm{eV}$ during $30 \mathrm{~min}$ at $77 \mathrm{~K}$. Just after, another illumination at $1.32 \mathrm{eV}$ is made (sequence 4 in Fig. 5). This energy does not play any effect on the EL2 centres which are in the metastable state. But for HM1, the effect is quite different considering the two hypothesis. The choice of an energy of $1.32 \mathrm{eV}$ is to optimize the ratio $\left(\sigma_{\mathrm{n} 1}^{0}\right) /\left(\sigma_{\mathrm{n} 1}^{0}+\sigma_{\mathrm{p} 1}^{0}\right)$. So, considering the TSCAP sequences 2 and 3 as illustrated in figure 5 , the difference between TSCAP2 (respectively TSCAP3) and TSCAP1 allow us to deduce the TSCAP of HM1 (respectively of EL2).

In order to obtain the step corresponding to HM1 (TSCAP2), we applied pulse voltage at $77 \mathrm{~K}$ to fill all HM1 levels with holes and rewarming under reverse bias. For EL2, illumination at $260 \mathrm{~K}$ with $h \nu=0.95 \mathrm{eV}$ during $5 \mathrm{~min}$ was used leading to a major part of the EL2 population full with electrons $\left(\sigma_{\mathrm{p} 2}^{0} / \sigma_{\mathrm{p} 2}^{0}+\sigma_{\mathrm{n} 2}^{0}\right.$ maximum at $\left.0.95 \mathrm{eV}\right)$. The absolute amplitude of TSCAP (EL2) is corrected taking into account the amplitude of $\Delta C$ due to EL2 in sequence 4. Figure 6 summarizes the results of the two TSCAP sequences, the capacitance steps give the concentration of HM1 and EL2 $\left(4 \times 10^{16} \mathrm{~cm}^{-3}\right.$ and $3.5 \times 10^{16} \mathrm{~cm}^{-3}$ respectively).

To prove the dependence of HM1 and EL2 levels, photo-quenching was made as described above. First, we compare the two TSCAP corresponding to a procedure with (sequence 4) and without (sequence 5) the quenching sequence (Fig. 5). Then, we try to interpret the difference (TSCAP4TSCAP5) in the two hypothesis. In the case where HM1 and EL2 are two independent defects, it is easy to see - according to equations given in figure 5 that the difference (4-5) does not include any TSCAP step due to HM1. In the case where HM1

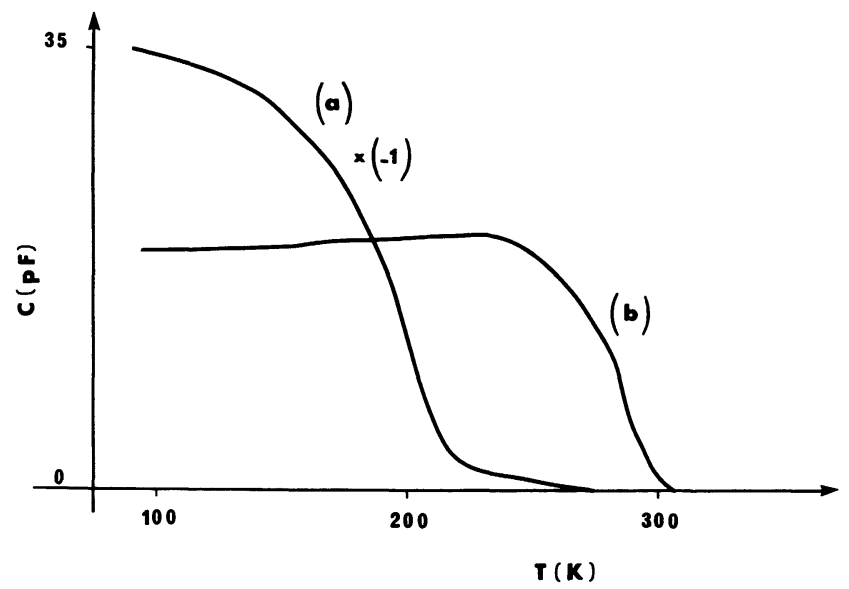

Fig. 6. - TSCAP spectra of HM1(a) and EL2(b) corresponding respectively to [(TSCAP2-TSCAP1), showing the response of HM1 alone] and [(TSCAP3-TSCAP1), showing the response of EL2 alone].

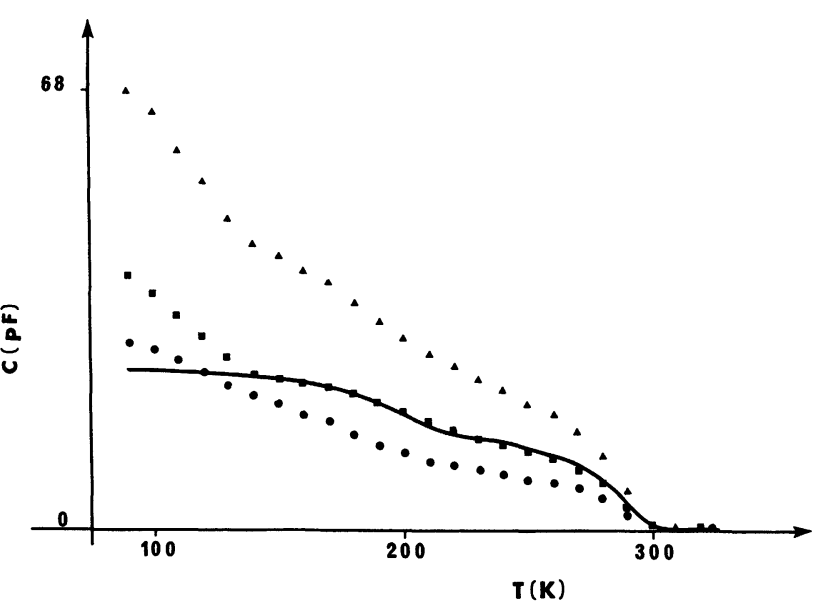

Fig. 7. - TSCAP curves obtained with the sequence 4 (EL2 quenched) (A) and sequence 5 (EL2 not quenched) $(\bullet)$ at $77 \mathrm{~K}$ and their difference $(\boldsymbol{\square})$. Solid line : fit with $A \times$ TSCAP (EL2) $+B \times$ TSCAP (HM1) with $A=0.65$ and $B=-0.35$. 
and EL2 are the two charge states of the same defect, this difference can be analysed as a linear combination of TSCAP steps due to HM1 and EL2. The TSCAP spectra of these two sequences are represented in figure 7. As we can see, their difference is well fitted by a linear combination of TSCAP (HM1) and TSCAP (EL2) given in figure 6. The corresponding equation is $A$. TSCAP (EL2) + $B$. TSCAP(HM1) with $A=0.65$ and $B=-0.35$.

It is possible to compare the numerical values of $A$ and $B$ given by the fit in figure 7 with the theoretical values calculated from the absolute optical cross sections of HM1 and EL2. A simple calculation shows that under illumination, the $(++)$ state population (HM1 full of holes giving the TSCAP (HM1) step) is given by $N_{\mathrm{T}} / K$ and the (0) charge state population (EL2 full of electrons giving the TSCAP (EL2) step) is given by :

$$
\frac{\sigma_{\mathrm{n} 1}^{0} \sigma_{\mathrm{n} 2}^{0}}{\sigma_{\mathrm{p} 1}^{0} \sigma_{\mathrm{p} 2}^{0}} \times \frac{N_{\mathrm{T}}}{K}
$$

with

$$
K=1+\frac{\sigma_{\mathrm{n} 2}^{0}}{\sigma_{\mathrm{p} 2}^{0}}+\frac{\sigma_{\mathrm{n} 2}^{0} \sigma_{\mathrm{n} 1}^{0}}{\sigma_{\mathrm{p} 2}^{0} \sigma_{\mathrm{p} 1}^{0}}
$$

$N_{\mathrm{T}}$ : total concentration of defects in the three charge states $(++,+$ and 0$)$.

For $h \nu=1.32 \mathrm{eV}$, the absolute photoionization spectra give $A=0.6$ and $B=-0.15$. Taking into account that the absolute optical cross sections are known at about a factor of 2 , the agreement is quite good. Therefore, we can assert that the Arsenic antisite isolated or in a complex form has two energy levels at $E_{\mathrm{v}}+0.52 \mathrm{eV}(\mathrm{HM} 1)$ and $E_{\mathrm{c}}-$ $0.82 \mathrm{eV}$ (EL2).

\section{Acknowledgments.}

Thanks are due to Wacker Chemitronic and to Dr. Molva (LETI) for the generous gift of many samples.

\section{References}

[1] Lagowski, J., Gatos, H. C., Parsey, J. M., WADA, K., KaminSKA, M. and WalUKIEWICZ, W., Appl. Phys. Lett. 43 (1983) 302.

[2] Martin, G. M. and Makram-Ebeid, S., The midgap donor level EL2 in GaAs in Deep Centers in Semiconductors, ed. by Pantelides, S. T. (Gordon and Breach) (1986) 399-487.

[3] Kaminska, M., Skowronski, M. and Kuszko, W., Phys. Rev. Lett. 55 (1985) 2204.

[4] Von Bardeleben, H. J., Stievenard, D., DeresMes, D., Huber, A. and Bourgoin, J. C., Phys. Rev. 34 (1986) 7192.

[5] Vincent, G., Bois, D. and Chantre, A., J. Appl. Phys. 53 (1982) 3643.

[6] Martin, G. M., Appl. Phys. Lett. 39 (1981) 747.

[7] Weber, E. R. and Schneider, J., Physica 166B (1983) 398.

[8] Wosinski, T., Appl. Phys. A 36 (1985) 213.

[9] LAgowsKi, J., LIN, D. G., CHEN, T. P.,
Skowronski, M. and Gatos, H. C., Appl. Phys. Lett. 47 (1985) 929.

[10] OsaKa, J., Окамото, H. and Kobayashi, K., Proceedings of the 4th Int. Conf. on SemiInsulating III-V Materials Conf. (Hakone, Japan) (ed. by Ohmsha Ltd) (1986) 421.

[11] Pelloie, J. L., Guillot, G., Nouailhat, A. and Antolini, A. G., J. Appl. Phys. 59 (1986) 1536.

[12] Bremond, G., Guillot, G., Nouailhat, A. and Picoli, G., J. Appl. Phys. 59 (1986) 2038.

[13] Vincent, G., Chantre, A. and Bois, D., J. Appl. Phys. 50 (1979) 5484.

[14] Kleverman, M., Omling, P., Ledebo, L. A. and Grimmeiss, M. G., J. Appl. Phys. 54 (1983) 814.

[15] Mitonneau, A., Martin, G. M. and Mircea, A., Electron. Lett. 13 (1977) 666.

[16] Chantre, A., Vincent, G. and Bois, D., Phys. Rev. 23 (1981) 5335. 